Buket Ertürk Şengel $\odot$

Özlem Alhan $\odot$

Rabia Can Sarınoğlu ๑

Elif Tükenmez Tigen $\odot$

Zekaver Odabaşı ๑

\title{
Pneumocystis jirovecii Positivity and Empirical Treatment Approach in Bronchoalveolar Lavage Samples
}

\section{öz}

Pneumocystis jirovecii (PJ) immünosupresif hastalarda pnömoniye sebep olan fırsatçı bir maya benzeri fungustur. En riskli grup HIV-pozitif hastalardır ancak son yıllarda HIV-negatif immünosuprese hastalarda daha sık görülmektedir. Bu çalışmada Marmara Üniversitesi Pendik Eğitim ve Araştırma Hastanesinde Pneumocystis jirovecii pnömonisi (PJP) ve diğer fırsatçı solunum yolu patojenleri şüphesi ile bronkoskopik örnekleri değerlendirilen hastalarda PJ polimeraz zincir reaksiyonu (PZR) pozitiflik oranı, hasta risk faktörleri, klinik ve laboratuvar bulgularını retrospektif olarak değerlendirilmiştir. Toplam 133 hastanın bronkoalveolar lavaj örneğinden PJ-PZR çalışılmış ve \% 13 (17/133) oranında pozitiflik bulunmuştur. PZR pozitif hastaların \% 41'inin HIV-pozitif ve \% 59'unun HIV-negatif immünosuprese hastalar olduğu görülmüştür. Örnek gönderilen hastaların 72'sine ampirik trimetroprim/sülfametoksazol başlanmış, PZR pozitif hastalarla beraber toplam 38 hastada tedaviye devam edilmiştir. PJ-PZR negatif 21 hastanın dokuzunda klinik yanıt alınmıştır ve başka bir enfeksiyon etkeni gösterilememiștir. Toplam 66 hastaya hipoksik olmaları nedeniyle steroid verilmiştir. Ampirik tedavi başlanan hastaların \% 24'ünde PJ-PZR pozitifliği ve \% 36'sının tedaviye yanıt verdiği görülmüştür. HIV-negatif immün suprese hastalarda PJP akla gelmeli ve gerekli örnek alındıktan ve ampirik tedaviye başlandıktan sonra başka bir etken gösterilemiyorsa ve yüksek klinik şüphe varsa tedaviye devam edilebilir.

Anahtar kelimeler: HIV, immünsupresyon, Pneumocystis jirovecii, polimeraz zincir reaksiyonu

\begin{abstract}
Pneumocystis jirovecii (PJ) is an opportunistic yeast-like fungus that causes pneumonia in immunosuppressed patients. The most risky group is HIV-positive patients, but in recent years it has been more common in HIV-negative immunosuppressed patients. In this study, PJ polymerase chain reaction (PCR) positivity rate, patient risk factors, clinical and laboratory findings were evaluated retrospectively in patients with suspected Pneumocystis jirovecii pneumonia (PJP) and other opportunistic respiratory pathogens at Marmara University Pendik Training and Research Hospital. Pneumocystis jirovecii PCR was studied from the bronchoalveolar lavage sample of a total of 133 patients, and $13 \%(17 / 133)$ were positive. Forty one \% of PCR positive patients were HIV-positive, and $59 \%$ were HIV-negative immunosuppressed patients. Empirical trimethoprim/sulfamethoxazole was initiated in 72 of the patients whose specimens were sent, and treatment was continued in 38 including PCR positive patients. Clinical response was obtained in 9 of 21 PJ PCR negative patients, and no other infectious agents were shown. A total of 66 patients were given steroids because they were hypoxic. Twenty four \% of patients who started empirical treatment had positive PJ $P C R$, and $36 \%$ responded to the treatment. In HIV-negative immunosuppressed patients, PJP should be considered, and treatment can be continued if no other factor could be shown and there is high suspicion after taking the required specimen and starting empirical treatment.
\end{abstract}

Keywords: HIV, immunosupression, Pneumocystis jirovecii, polymerase chain reaction

Received/Geliş: 15.06.2020
Accepted/Kabul: 17.07.2020
Published Online/Online Yayın: 31.08.2020

Atıf/Cite as: Ertürk Şengel B, Alhan Ö, Can Sarınoğlu R, Tükenmez Tigen E, Odabașı Z. Bronkoalveolar lavaj örneklerinde Pneumocystic jirovecii pozitifliği ve ampirik tedavi yaklaşımı. ANKEM Derg. 2020;34(2):57-64.

Buket Ertürk Şengel Marmara Üniversitesi Tıp Fakültesi, Enfeksiyon Hastalıkları ve Klinik Mikrobiyoloji Anabilim Dalı, İstanbul - Türkiye - besengel@gmail.com ORCID: 0000-0003-2182-4693

Ö. Alhan 0000-0002-2540-7945 E. T. Tigen 0000-0003-2027-4116 Z. Odabaşı 0000-0001-8091-6999 Marmara Üniversitesi Tıp Fakültesi, Enfeksiyon Hastalıkları ve Klinik Mikrobiyoloji Anabilim Dali, Istanbul - Türkiye

R. C. Sarınoğlu 0000-0002-7597-8279 Marmara Üniversitesi Tıp Fakültesi, Tıbbi Mikrobiyoloji Anabilim Dalı istanbul - Türkiye 


\section{Giriş}

Pneumocystis jirovecii (eski adıyla Pneumocystis carinii) özellikle immün sistemi bakılanmış kişilerde yaşamı tehdit eden pnömonilere sebep olur. Özellikle T hücre fonksiyonlarının baskılandığı hasta gruplarında risk belirgin artar. CD4 sayısı $<200 / \mathrm{mm}^{3}$ olan HIVpozitif hastalar en riskli grup olmakla beraber, hematolojik maligniteler, kök hücre ve solid organ nakli, yüksek doz steroid ve kanser tedavisinde kullanılan kemoterapi ajanları diğer önemli risk faktörleridir ${ }^{(20)}$. HIV-pozitif hastalarda erken tanı, antiretroviral tedavi (ART) ve profilaksi sayesinde P.jirovecii pnömonisi (PJP) insidansı azalmaktadır ${ }^{(15)}$. Bununla beraber HIVnegatif immünosuprese hasta sayısının her geçen gün artması nedeniyle bu grupta PJP sıklığında belirgin artış görülmektedir ${ }^{(17)}$.

İmmün sistemi baskılanmış hastalarda pnömoni etiyolojisinde fırsatçı etkenler de sık görüldüğü için tanı amacı ile alınan solunum örneklerinde P.jirovecii, Nocardia spp., atipik mikobakteri, Mycobacterium tuberculosis ve bazı viral etkenler için de sıklıkla testler istenmektedir. Bu hastalarda özellikle interstisyel infiltrat ve genel durum bozukluğu varlığında mortalitesinin yüksek olması nedeniyle sıklıkla PJP'ye yönelik ampirik tedavi başlanmaktadır. Ampirik veya kanıtlanmış PJP tedavisinde ilk tercih ilaç trimetoprim/sülfametoksazoldür (TMP/SMX), bu ilacın önemli yan etkileri olduğu da unutulmamalıdır.

Bu çalışmada amacımız, son dört yılda Marmara Üniversitesi Pendik Eğitim ve Araştırma Hastanesi'nde ayırıcı tanısında PJP düşünülen ve bronkoskopik solunum örnekleri alınan hastalarda P. jirovecii pozitifliği, hasta risk faktörleri, klinik ve laboratuvar bulgularının değerlendirilmesidir.

\section{GEREÇ VE YÖNTEM}

Bu çalışmada Mayıs 2016-Mayıs 2020 tarihleri arasında Marmara Üniversitesi Pendik Eğitim ve Araştırma Hastanesi'nde yatan veya ayaktan başvuran $\geq 18$ yaş hastalardan PJP ön tanısı ile bronkoalveolar lavaj sIVISI (BAL) örneğinden PZR istenilen hastalar retrospektif olarak taranmıştır. Bu örneklerin PJP açısından pozitiflik oranı ve hasta risk faktörleri, tanı anındaki semptomları, akciğer tomografileri, laboratuvar bulguları (lenfosit sayısı, laktat dehidrogenaz (LDH), C-reaktif protein (CRP)) ve ampirik tedavileri değerlendirilmiştir. Risk faktörleri arasında değerlendirilen izole steroid kullanımı, en az 2 hafta süre ile $20 \mathrm{mg} / g u ̈ n$ prednizolon ve eşdeğeri preparatların kullanımı olarak tanımlanmıştır. BAL örneklerinden P.jirovecii DNA izolasyonu, amplifikasyonu ve saptanması tam otomatize olarak Elite in Genius sisteminde (ELITech Group, Italya) validasyona sahip Rida ${ }^{\circledR}$ Gene P.jirovecii "real-time" PZR kiti (R-Biopharm AG, Almanya) ile kalitatif olarak çalışılmıştır. PZR inhibisyonunu kontrol etmek için her örnek için internal kontrol ve her çalışmada pozitif ve negatif kontroller çalışılımıştır.

\section{İstatistik}

Çalışmamız retrospektif ve tanımlayıcıdır. Tanımlayıcı değişkenler, frekans, yüzdelik, ortalama, standart sapma, ortanca ve persentillerle değerlendirilmiştir. Kategorik değişkenlerin karşılaştırılması amacıyla ki-kare ve gereğinde Fisher analizleri kullanılmıştır. İstatistiksel hesaplamalarda SPSS programı (versiyon 22.0, SPSS Inc., Chicago, USA) kullanılmıştır.

\section{BULGULAR}

Dört yıllık süre içinde toplam 133 hastanın BAL örneğinde PJ-PZR çalışılmıştır ve 17 (\% 13) hastada pozitiflik saptanmıştır. En sık hematolojik malignite ve solid tümörü olan ve bu sebeplerle kemoterapi alan hastalardan örnek gönderilmiştir. Hastaların 9'u hariç hepsinde HIV serolojisi bakılmıştır ve toplam 16 hastada pozitiflik saptanmıştır. On dokuz (\% 14) hastada romatolojik hastalık ( $n=6)$, pulmoner hastalık $(n=5)$, renal hastalık $(n=4)$, splenektomiye bağlı trombositopeni $(n=2)$ nedeni ile izole steroid kullanımı tespit edilmiştir. İki hastada neden bilinmemektedir. On yedi hastada altta yatan herhangi bir risk faktörü gösterilememiştir. BAL örneğinde PJ-PZR çalışılan tüm hastaların ve pozitif sonuçlanan hastaların demografik özellikleri, risk faktörleri, başvuru esna- 
Tablo 1. Pneumocystis jirovecii PZR çalışlan tüm hastalar ve pozitif sonuçlanan hastaların karakteristik özellikleri, risk faktörleri ve klinik sonuçları.

\begin{tabular}{|c|c|c|}
\hline Değişkenler & $\begin{array}{l}\text { Toplam hasta } \\
(n=133)\end{array}$ & $\begin{array}{l}\text { PJ-PZR pozitif hasta } \\
\qquad(n=17)\end{array}$ \\
\hline Yaş [ortanca (25-75 persentil)] & $51(39-64)$ & $49(28-53)$ \\
\hline \multicolumn{3}{|l|}{ Cinsiyet [n (\%)] } \\
\hline Erkek & $87(65)$ & $11(65)$ \\
\hline Kadın & $46(35)$ & $6(35)$ \\
\hline \multicolumn{3}{|l|}{ Altta yatan hastalık [n (\%)] } \\
\hline Hematolojik malignite & $50(37)$ & $4(23)$ \\
\hline Solid organ tümör & $22(16)$ & $1(6)$ \\
\hline HIV pozitif & $16(12)$ & $7(41)$ \\
\hline Kök hücre nakli & $8(6)$ & $1(6)$ \\
\hline Böbrek nakli & $6(4)$ & 0 \\
\hline İzole steroid kullanımı & $19(14)$ & $4(23)$ \\
\hline Son bir ayda kemoterapi/immünosupresif ajan kullanımı & $79(59)$ & $7(5)$ \\
\hline \multicolumn{3}{|l|}{ Semptomlar [n (\%)] } \\
\hline Nefes darlığı & $85(64)$ & $10(59)$ \\
\hline Öksürük & $78(59)$ & $10(59)$ \\
\hline Ateş & $71(53)$ & $13(76)$ \\
\hline Hipoksi & $85(64)$ & $9(53)$ \\
\hline \multicolumn{3}{|l|}{ BT bulguları [n (\%)] } \\
\hline Buzlu cam & $87(65)$ & $15(88)$ \\
\hline Konsolidasyon & $62(47)$ & $5(29)$ \\
\hline Plevral efüzyon & $47(35)$ & 0 \\
\hline Nodül & $30(22)$ & $1(6)$ \\
\hline Retiküler infiltrat & $19(14)$ & $2(12)$ \\
\hline \multicolumn{3}{|l|}{ Laboratuvar bulguları } \\
\hline Nötropeni $(<500 \mu \mathrm{L})$ & $14(10)$ & $1(6)$ \\
\hline Lenfopeni $(<800)$ & $77(58)$ & $14(82)$ \\
\hline CRP, mg/L ortanca ( $25-75$ persentil) & $108(55-155)$ & $98(58-115)$ \\
\hline LDH, U/L ortanca (25-75 persentil) & $442(304-682)$ & $424(339-939)$ \\
\hline Profilaksi [n (\%)] & $6(4)$ & $2(12)$ \\
\hline \multicolumn{3}{|l|}{ Sonuç [n (\%)] } \\
\hline Taburcu & $78(59)$ & $15(88)$ \\
\hline Ölüm & $55(41)$ & $2(12)$ \\
\hline
\end{tabular}

CRP; C reaktif protein, $L D H ;$ Laktat dehidrogenaz

sındaki semptomları, laboratuvar değerleri ve radyolojik bulguları Tablo 1'de özetlenmiştir.

PJ-PZR pozitif hastaların 7/17'sinde (\% 41) HIVpozitifliği görülmüştür. HIV-pozitif ve negatif hastaların dağılımı Tablo 2'de özetlenmiştir.

Klinik ve radyolojik bulguları nedeniyle toplam 72 (\% 54) hastaya ampirik TMP/SMX başlanmıştır, bu hastaların 66'sına ek olarak steroid de verilmiştir. PZR pozitif saptanan hastaların hepsi 21 gün TMP-SMX ve steroid tedavisi almıştır. Ampirik tedavi başlanıp PZR negatif gelen 55 hastanın 34'ünde PJ dışı etiyoloji gösterildiği için TMP/SMX tedavisi kesilmiştir. Kalan 21 hastada bariz bir etken gösterilememesi veya kri- tik durumda olmaları nedeniyle tedaviye devam edilmiştir. Bu hastaların 9/21'inde (\% 43) tedaviye yanıt alınmıştır, yanıt alınamayan 12 hastanın altısı kaybedilmiştir.

Tüm PJ-PZR negatif saptanan hastaların solunum yollarında en sık izole edilen patojenler Acinetobacter baumannii, Enterobacteriaceae spp., Pseudomonas aeruginosa ve Gram pozitif bakterilerdir. Toplam 16 hastada birden fazla bakteri gösterilmiştir. Örnek gönderilen tüm hastaların 55'i (\% 41) kaybedilmiştir. PJP olan hastaların 2/17'sinde (\% 12) mortalite gelişmiştir, bu iki hasta HIV-negatif olup romatolojik hastalıklar nedeniyle steroid kullanımı olan hastalardır. 
Tablo 2. Pneumocystis jirovecii PZR pozitif hastaların $(n=17)$ dağılımı.

\begin{tabular}{|c|c|c|}
\hline Değişkenler & $\begin{array}{c}\text { HIV pozitif } \\
(n=7)\end{array}$ & $\begin{array}{l}\text { HIV negatif } \\
\quad(n=10)\end{array}$ \\
\hline Yaş [ortanca (25-75 persentil)] & $41(38-50)$ & $51(25-59)$ \\
\hline \multicolumn{3}{|l|}{ Cinsiyet [n (\%)] } \\
\hline Erkek & $6(86)$ & $4(40)$ \\
\hline Kadın & $1(14)$ & $6(60)$ \\
\hline \multicolumn{3}{|l|}{ Semptomlar [n (\%)] } \\
\hline Nefes darlığı & $4(57)$ & $6(60)$ \\
\hline Öksürük & $5(71)$ & $5(50)$ \\
\hline Ateş & $6(86)$ & $7(70)$ \\
\hline Hipoksi & $3(43)$ & $6(60)$ \\
\hline \multicolumn{3}{|l|}{ BT bulguları [n (\%)] } \\
\hline Buzlu cam & $6(86)$ & $9(90)$ \\
\hline Konsolidasyon & $2(28)$ & $3(30)$ \\
\hline Plevral efüzyon & 0 & 0 \\
\hline Nodül & 0 & $1(10)$ \\
\hline Retiküler infiltrat & $2(28)$ & 0 \\
\hline \multicolumn{3}{|l|}{ Laboratuvar bulguları } \\
\hline Lenfopeni $(<800)$ & $6(86)$ & $8(80)$ \\
\hline CRP, mg/L ortanca (25-75 persentil) & $60(40-113)$ & $101(73-127)$ \\
\hline LDH, U/L ortanca (25-75 persentil) & $389(311-556)$ & $468(342-940)$ \\
\hline CD4, ortanca (25-75 persentil) & & Geçerli değildir \\
\hline$\%$ & $3(2-4)$ & \\
\hline Sayı, hücre/mikroL & $15(12-18)$ & \\
\hline Profilaksi [n (\%)] & $1(14)$ & $1(10)$ \\
\hline \multicolumn{3}{|l|}{ Sonuç [n (\%)] } \\
\hline Taburcu & $7(100)$ & $8(80)$ \\
\hline Ölüm & 0 & 2 \\
\hline
\end{tabular}

CRP; C reaktif protein, $L D H$; Laktat dehidrogenaz

İki hastada profilaksi altında PJP gelişmiştir. Bu hastalardan biri HIV-pozitif, diğeri aplastik anemi nedeniyle kök hücre nakli yapılmış hastadır.

\section{TARTIŞMA}

Bu çalışmada hastanemizde son dört yılda BAL örneklerinde çalışılan PJ-PZR sonuçları taranarak pozitiflik oranları, hasta risk faktörleri, klinik ve laboratuvar bulguları irdelenmiştir.

Özellikle immün sistemi baskılanmış hastalarda karşımıza çıkan PJP'nin herhangi bir risk faktörü olmadan görülmesi oldukça nadirdir ${ }^{(6,7)}$. Çalışmamızda PJ-PZR pozitif tüm hastalarda en az bir risk faktörü saptanmıştır. BAL örnekleri değerlendirilen tüm hastaların çoğunluğunda bilinen bir risk faktörü varken, 17 (\% 13) hastada herhangi bir risk faktörü olmadığı halde örnek gönderilmiş olduğu tespit edilmiştir ve bu hastalarda PJ-PZR negatif sonuçlanmıştır.

HIV ile enfekte hastalar en önemli risk grubunu oluşturmaktadır ve birçok çalışmada hastalar HIVpozitif ve HIV-negatif olarak gruplandırılmaktadır ${ }^{(8,12)}$. Benzer şekilde bizim çalışmamızda da PJ-PZR pozitif saptanan hastaların 7/17'sinde (\% 41) HIV pozitifliği görülmüştür. HIV-pozitif hastaların erken tanı, antiretroviral tedavi ve CD4 sayısı $<200 / \mathrm{mm}^{3}$ olan hastalara verilen PJ profilaksisi ile görülme sıklığı giderek azalmaktadır. Buna karşın, HIV-negatif immünosuprese hastalarda ise (malignite, hematolojik, otoimmün hastalıklar gibi) son zamanlarda kematerapötik ilaçlardaki gelişmeyle risk altındaki hasta sayısı da her geçen gün artmaktadır(18). Literatürle uyumlu olarak bizim hastalarımızın da yarıdan fazlası HIVnegatiftir. 
PJP'de ateş ve nefes darlığı altta yatan hastalıktan bağımsız olarak en sık karşılaşılan semptomlardır. Hemen hemen tüm hastalarda oda havasında hipoksemi görülür ${ }^{(18)}$. Çalışmamızda PJ-PZR pozitif hastalarda en sık görülen semptom ateştir. Hastalarda \% 59 oranında nefes darlığı ve öksürük görülmüştür. Semptomlar benzer olmasına karşın, ortaya çıkış süresi HIV-negatif ve pozitif hastalarda farklılık göstermektedir. Birçok çalışma HIV-negatif hastaların istatistiksel olarak anlamlı derecede daha kısa semptom süresine sahip olduğunu göstermiştir ${ }^{(12,18)}$.

Görüntüleme için yüksek rezolüsyonlu bilgisayarlı tomografi (BT) düz grafiden daha duyarlıdır ve genellikle bilateral, diffüz buzlu cam manzarası görülür ${ }^{(2,18)}$. Kistik veya özellikle HIV-negatif hastalarda nodüler lezyonlar da görülebilmektedir(16). Risk grubundaki hastalar başvurduğunda hipoksi ile birlikte BT'de diffüz buzlu cam manzarası görüldüğünde ilk akla gelen PJP olmasına rağmen akut intersitisyel pnömoni, hipersensivite pnömonisi, idiyopatik pulmoner fibrozis, sarkoidoz, mikoplazma ve viral pnömoniler, pulmoner hemoraji ve akut eozinofilik akciğer hastalığı gibi birçok hastalıkta da görülebileceği göz önünde bulundurulmalıdır(25). Semptom süresinde olduğu gibi radyolojik bulgular da HIV-pozitif ve negatif hastalarda farklılıklar gösterebilmektedir. Tasaka ve ark. ${ }^{(18)}$, yaptıkları çalışmada HIV-negatif maligniteli PJP hastaların BT'sinde buzlu cam manzarasına eşlik eden konsolidasyon gözlemiş, HIV-pozitif hastaların hiçbirinde konsolidasyon görmemişlerdir $(p<0.01)$. Bizim çalışmamızda da PJ-PZR pozitif hastaların $\% 88^{\prime}$ inde buzlu cam manzarası olduğu görülmüştür. HIV-pozitif ve negatif hastalar ayrı ayrı incelendiğinde ise her iki grupta da en sık radyolojik bulgu olarak buzlu cam manzarası tespit edilmiştir. Konsolidasyon her iki grupta da hastaların yaklaşık üçte birinde karşımıza çıkmıştır.

Tanıda, P.jirovecii kültürde üretilemediği için serolojik ve/veya moleküler yöntemler gibi kültür dışı hızlı sonuç verebilen testler tercih edilmektedir. Solunum örneklerinde direkt mikroskopik inceleme ile hızlı sonuç alınabilmektedir. Ancak, değerlendirme için tecrübe önemlidir ve duyarlılığı fungal yüke bağlı olarak değişmektedir. Bu nedenle yalancı negatiflik görülebilir ${ }^{(21)}$. Mantar hücre duvarı komponenti olan $\beta$-glukanın serumda tespiti HIV-pozitif hastalarda sensivitesi ve negatif prediktif değeri yüksek olan bir testtir. Ancak HIV-negatif ve fungal yük düşük hastalarda duyarlılığı düşüktür(19). Günümüzde en değerli tanı yöntemi solunum yolu örneklerinde etkenin PZR ile tespitidir. Hem hızlı hem de duyarlıı̆̆ yüksek olması nedeniyle direkt mikroskopik incelemeden üstündür ${ }^{(23)}$. Alshahrani ve ark.'nın ${ }^{(1)}$ yaptığı çalışmada yüksek şüpheli 39 hastadan alınan BAL örneklerinde tüm hastalarda PJ-PZR pozitif bulunmuştur. Sensivitesi ve spesifitesi oldukça yüksek bir testtir fakat kolonizasyon ve enfeksiyon ayrımı yapamaz. Çalışmamızda 133 hastadan PJ-PZR gönderilmiş ve 17 (\% 13) hastada pozitiflik saptanmıştır. Merkezimizde immünosuprese veya etiyolojisi araştırılan hastalarda yüksek şüphe olmasa da görüntülemede buzlu cam ya da retiküler infiltrat saptanırsa BAL örneği alındığında bakteriyel kültür, mikobakteri kültürü, viral panel gibi tetkiklerin yanında PJ-PZR da rutin olarak istenmektedir.

Örnek gönderilen hastalardan 72'sine (\% 54) ampirik tedavi başlanmıştır. Diğer 61 hastaya başlanmamasının nedeni kliniklerinin hafif olması veya örnek gönderilmiş olmasına rağmen PJP şüphesinin düşük olması olabilir. Ampirik tedavi başlanan 72 hastanın 17'sine PZR pozitif geldiği için, 21 hastaya ise yüksek şüphe ve solunum yollarında başka bir etken gösterilememesi nedeniyle tedaviye devam edilmiştir. Dokuz (\% 43) hastada PZR negatifliğine rağmen tedaviyle klinik yanıt alınmıştır. PJP için risk faktörü olan 116 hastadan PZR istendiğinde 17/116 (\% 15) hastada pozitiflik görülmüştür. Ampirik tedavi başlanan 72 hastanın 17'sinde PJ-PZR pozitif geldiği düşünüldüğünde \% 24 oranında pozitiflik saptanmış ve PZR negatif saptanan 9 hastayla beraber toplam 26 (\% 36) hastada tedaviye klinik yanıt alınmıştır.

PJP'de semptomlar ve radyolojik bulgular spesifik olmadığından ayırıcı tanı çok önemlidir. Tanı için gerekli örnekler alındıktan sonra erken ampirik tedavi için günümüzde en etkili ve ilk tercih edilen ajan olan TMP/SMX'dür. HIV enfekte hastalarda tedavi 
süresi net olarak 21 gün iken, HIV-negatiflerde yeteri kadar çalışma olmamakla beraber fulminan seyir ve kötü prognoz göz önüne alınarak yine 21 gün önerilmektedir ${ }^{(10)}$. Çalışmamızda PJ-PZR pozitif saptanan hastaların hepsine 21 gün tedavi verilmiştir. TMP/SMX'un hayat kurtarıcı etkisi yanında hematolojik ve renal yan etkileri nedeniyle dikkatli kullanılması gerekmektedir.

HIV dışı risk faktörleri olan malign hastalıklar, kemoterapi, kök hücre veya solid organ nakli ve kortikosteroid kullanımı da T hücre baskılanması yaparak PJP riskini arttırmaktadır ${ }^{(4)}$. Retrospektif bir çalışmada 8 hafta $\geq 16 \mathrm{mg} /$ gün prednizolon ile tedavi edilen HIV-negatif hastalarda PJP riskinin anlamlı olarak arttığı gösterilmiştir(24). Matsumura ve ark. ${ }^{(14)}$ HIV negatif hastalarda steroid kullanımı ve hücresel immün sistem baskılanmasının PJP için en önemli risk faktörleri olduğunu belirtmişlerdir. Bizim çalışmamızda PJP şüphesiyle örnek gönderilen 19 hastada izole steroid kullanımı olduğu tespit edilmiş ve bu hastaların dördünde (\% 21) PJ-PZR pozitif bulunmuştur.

Steroid bir risk faktörü olmasına rağmen oda havasında parsiyel $\mathrm{O}_{2}$ basıncı $<70 \mathrm{mmHg}$ ve/veya alveolar-arteryel $\mathrm{O}_{2}$ gradyenti $>35 \mathrm{mmHg}$ olan hastalarda mortalite üzerine olumlu etkisi nedeniyle önerilmektedir(5). Birçok çalışmada hipoksik HIVpozitif PJP hastalarında steroid eklemenin belirgin faydası gösterilmiştir ${ }^{(3,11)}$. Bununla birlikte HIV-negatif PJP hastalarında steroid kullanımı tartışmalıdır, hatta bazı çalışmalar mortaliteyi arttırdığını göstermektedir ${ }^{(9,22)}$. "European Conferance on Infection and Leukaemia" (ECIL) kılavuzu solunum yetmezliği ve PJP olan hematolojik maligniteli, HIV-negatif hastalarda steroid kullanımını önermemektedir ${ }^{(13)}$. Çalışmamızda PJP şüphesi ile ampirik TMP-SMX başlanan 72 hastanın 66'sına (HIV negatif hastalar dahil) hipoksi nedeniyle steroid eklenmiş olduğu görülmüştür.

PJP, HIV negatif immünosuprese hastalarda hastalık HIV-pozitiflere göre daha hızlı ilerler ve kötü prognozludur ${ }^{(12)}$. Efektif tedaviye rağmen bu hastalarda mortalite oldukça yüksek bulunmuştur (\% 19-76)
(22). Çalışmamızda kaybedilen iki PJP vakası da HIVnegatif gruptandır. Bu grupta mortalite oranı \% 20 'dir.

Çalışmamızın bazı kısıtıııkları vardır. İlk olarak çalışmamızda az sayıda PJ-PZR pozitif hasta ile değerlendirme yapılmıştır. İkincisi, HIV-pozitif ve negatif hastaların semptom başlangıçlarından tedavi başlangııına kadarki sürelerine ulaşılamamasıdır. Üçüncüsü, BAL; hastanın kliniği, laboratuvar parametreleri ve fiziki imkanlar göz önüne alındığında her zaman kolaylıkla yapılabilen bir işlem olmadığından örnek alındıktan sonra, ön tanı düşünülmeksizin, her laboratuvara gönderilmektedir. Çalışmamızda 17 hastadan risk faktörü olmadığı halde örnek gönderilmiş olması da bu durumu desteklemektedir. Son olarak ilaç yan etkileri ve bu etkilere bağlı tedavi kesilmeleri değerlendirilememiştir.

Sonuç olarak PJP artık sadece HIV-pozitif hastalarda değil HIV-negatif immünosuprese hastalarda da giderek artmaktadır. Şüphelenilen hastalardan gerekli örnekler alınarak geç kalınmadan ampirik tedavi başlanmalıdır. PZR'nin sensivitesi yüksek olmasına rağmen negatif sonuçlanan yüksek şüpheli hastalarda ampirik tedaviye devam edilmesi hayat kurtarıcı olabilir.

Etik Kurul Onayı: Marmara Üniversitesi Tıp Fakültesi Klinik Araştırmalar Etik Kurulu'nun onayı alınmıştır (09.2020.661).

Çıkar Çatışması: Yazarlar tarafından herhangi bir çıkar çatışması bildirilmemiştir.

Ethics Committee Aproval: Aproval of Clinical Research Ethics Committee of Marmara University Faculty of Medicine was obtained (09.2020.661).

Conflict of Interest: No conflict of interest was declared by the authors.

\section{KAYNAKLAR}

1. Alshahrani MY, Alfaifi M, Ahmad I, et al. Pneumocystis Jirovecii detection and comparison of multiple diagnostic methods with quantitative real-time PCR in patients with respiratory symptoms. Saudi J Biol Sci. 2020;27(6):1423-7. 
https://doi.org/10.1016/j.sjbs.2020.04.032

2. Bollee G, Sarfati C, Thiery G, et al. Clinical picture of Pneumocystis jiroveci pneumonia in cancer patients. Chest. 2007;132(4):1305-10.

https://doi.org/10.1378/chest.07-0223

3. Delclaux C, Zahar JR, Amraoui G, et al. Corticosteroids as adjunctive therapy for severe Pneumocystis carinii pneumonia in non-human immunodeficiency virusinfected patients: retrospective study of 31 patients. Clin Infect Dis. 1999;29(3):670-2.

https://doi.org/10.1086/598651

4. Ding L, Huang $\mathrm{H}$, Wang $\mathrm{H}$, et al. Adjunctive corticosteroids may be associated with better outcome for non-HIV Pneumocystis pneumonia with respiratory failure: a systemic review and meta-analysis of observational studies. Ann Intensive Care. 2020;10(1):34.

https://doi.org/10.1186/s13613-020-00649-9

5. Ewald H, Raatz H, Boscacci R, et al. Adjunctive corticosteroids for Pneumocystis jiroveci pneumonia in patients with HIV infection. Cochrane Database Syst Rev. 2015(4):CD006150.

https://doi.org/10.1002/14651858.CD006150.pub2

6. Ide H, Yamaji Y, Tobino K, et al. Pneumocystis jirovecii pneumonia in an immunocompetent Japanese man: a case report and literature review. Case Rep Pulmonol. 2019;2019:3981681.

https://doi.org/10.1155/2019/3981681

7. Jacobs JL, Libby DM, Winters RA, et al. A cluster of Pneumocystis carinii pneumonia in adults without predisposing illnesses. N Engl J Med. 1991;324(4):24650.

https://doi.org/10.1056/NEJM199101243240407

8. Kato H, Samukawa S, Takahashi H, et al. Diagnosis and treatment of Pneumocystis jirovecii pneumonia in HIV-infected or non-HIV-infected patientsdifficulties in diagnosis and adverse effects of trimethoprim-sulfamethoxazole. J Infect Chemother. 2019;25(11):920-4.

https://doi.org/10.1016/j.jiac.2019.06.007

9. Lemiale V, Debrumetz A, Delannoy A, et al. Adjunctive steroid in HIV-negative patients with severe Pneumocystis pneumonia. Respir Res. 2013;14:87. https://doi.org/10.1186/1465-9921-14-87

10. Limper AH, Offord KP, Smith TF, et al. Pneumocystis carinii pneumonia. Differences in lung parasite number and inflammation in patients with and without AIDS. Am Rev Respir Dis. 1989;140(5):1204-9. https://doi.org/10.1164/ajrccm/140.5.1204

11. Limper AH, Knox KS, Sarosi GA, et al. An official American Thoracic Society statement: treatment of fungal infections in adult pulmonary and critical care patients. Am J Respir Crit Care Med. 2011;183(1):96-
128.

https://doi.org/10.1164/rccm.2008-740ST

12. Liu CJ, Lee TF, Ruan SY, et al. Clinical characteristics, treatment outcomes, and prognostic factors of Pneumocystis pneumonia in non-HIV-infected patients. Infect Drug Resist. 2019;12:1457-67.

https://doi.org/10.2147/IDR.S199761

13. Maschmeyer G, Helweg-Larsen J, Pagano L, et al. ECIL guidelines for treatment of Pneumocystis jirovecii pneumonia in non-HIV-infected haematology patients. J Antimicrob Chemother. 2016;71(9):240513.

https://doi.org/10.1093/jac/dkw158

14. Matsumura $\mathrm{Y}$, Ito $\mathrm{Y}$, Yamamoto $\mathrm{M}$, et al. Pneumocystis polymerase chain reaction and blood (1-->3)-beta-Dglucan assays to predict survival with suspected Pneumocystis jirovecii pneumonia. J Infect Chemother. 2014;20(2):109-14.

https://doi.org/10.1016/j.jiac.2013.09.004

15. Mirani G, Williams PL, Chernoff $M$, et al. Changing trends in complications and mortality rates among US youth and young adults with HIV infection in the era of combination antiretroviral therapy. Clin Infect Dis. 2015;61(12):1850-61. https://doi.org/10.1093/cid/civ687

16. Otahbachi M, Nugent K, Buscemi D. Granulomatous Pneumocystis jiroveci pneumonia in a patient with chronic lymphocytic leukemia: a literature review and hypothesis on pathogenesis. Am J Med Sci. 2007;333(2):131-5. https://doi.org/10.1097/00000441-200702000-00014

17. Salzer HJF, Schafer G, Hoenigl M, et al. Clinical, diagnostic, and treatment disparities between HIVinfected and non-HIV-infectedi patients with Pneumocystis jirovecii pneumonia. Respiration. 2018;96(1):52-65. https://doi.org/10.1159/000487713

18. Tasaka S, Tokuda H, Sakai F, et al. Comparison of clinical and radiological features of pneumocystis pneumonia between malignancy cases and acquired immunodeficiency syndrome cases: a multicenter study. Intern Med. 2010;49(4):273-81. https://doi.org/10.2169/internalmedicine.49.2871

19. Theel ES, Jespersen DJ, Iqbal S, et al. Detection of (1, 3)-beta-D-glucan in bronchoalveolar lavage and serum samples collected from immunocompromised hosts. Mycopathologia. 2013;175(1-2):33-41. https://doi.org/10.1007/s11046-012-9579-y

20. Thomas CF Jr., Limper AH. Current insights into the biology and pathogenesis of Pneumocystis pneumonia. Nat Rev Microbiol. 2007;5(4):298-308. https://doi.org/10.1038/nrmicro1621

21. White PL, Backx M, Barnes RA. Diagnosis and mana- 
gement of Pneumocystis jirovecii infection. Expert Rev Anti Infect Ther. 2017;15(5):435-47.

https://doi.org/10.1080/14787210.2017.1305887

22. Wieruszewski PM, Barreto JN, Frazee E, et al. Early corticosteroids for Pneumocystis pneumonia in adults without HIV are not associated with better outcome. Chest. 2018;154(3):636-44. https://doi.org/10.1016/j.chest.2018.04.026

23. Wilson JW, Limper AH, Grys TE, et al. Pneumocystis jirovecii testing by real-time polymerase chain reaction and direct examination among immunocompetent and immunosuppressed patient groups and correlation to disease specificity. Diagn Microbiol Infect Dis. 2011;69(2):145-52.

https://doi.org/10.1016/j.diagmicrobio.2010.10.021

24. Yale SH, Limper AH. Pneumocystis carinii pneumonia in patients without acquired immunodeficiency syndrome: associated illness and prior corticosteroid therapy. Mayo Clin Proc. 1996;71(1):5-13. https://doi.org/10.4065/71.1.5

25. Zompatori M, Rimondi MR. Diffuse ground-glass opacity of the lung. A guide to interpreting the highresolution computed tomographic (HRCT) picture. Radiol Med. 1994;88(5):576-81. 